Article

\title{
A New Agro/Forestry Residues Co-Firing Model in a Large Pulverized Coal Furnace: Technical and Economic Assessments
}

\author{
Weigang Xu, Yanqing Niu *, Houzhang Tan, Denghui Wang, Wenzhi Du and Shien Hui \\ Ministry of Education (MOE), Key Laboratory of Thermo-Fluid Science and Engineering, Department of \\ Thermal Engineering, School of Energy and Power Engineering, Xi'an Jiaotong University, \\ Shaanxi 710049, China; E-Mails: xuweigang79@stu.xjtu.edu.cn(W.X.); tanhz@mail.xjtu.edu.cn (H.T.); \\ tiantangren1989@163.com (D.W.); duwenzhi37@stu.xjtu.edu.cn (W.D.); sehui@mail.xjtu.edu.cn (S.H.) \\ * Authors to whom correspondence should be addressed; E-Mails: yqniu85@mail.xjtu.edu.cn; \\ Tel.: +86-137-091-81734; Fax: +86-29-826-68703.
}

Received: 9 April 2013; in revised form: 1 August 2013 / Accepted: 5 August 2013 / Published: 23 August 2013

\begin{abstract}
Based on the existing biomass co-firing technologies and the known innate drawbacks of dedicated biomass firing, including slagging, corrosion and the dependence on fuel, a new model of agro/forestry residue pellets/shreds and coal co-fired in a large Pulverized Coal (PC) furnace was proposed, and the corresponding technical and economic assessments were performed by co-firing testing in a $300 \mathrm{MW}$ PC furnace and discounted cash flow technique. The developed model is more dependent on injection co-firing and combined with co-milling co-firing. Co-firing not only reduces $\mathrm{CO}_{2}$ emission, but also does not significantly affect the fly ash use in cement industry, construction industry and agriculture. Moreover, economic assessments show that in comparison with dedicated firing in grate furnace, agro/forestry residues and coal co-firing in a large PC furnace is highly economic. Otherwise, when the co-firing ratio was below $5 \mathrm{wt} \%$, the boiler co-firing efficiency was $0.05 \%-0.31 \%$ higher than that of dedicated PC combustion, and boiler efficiencies were about $0.2 \%$ higher with agro/forestry residues co-firing in the bottom and top burner systems than that in a middle burner system.
\end{abstract}

Keywords: co-firing; agro/forestry residues; mill; $\mathrm{CO}_{2} / \mathrm{NO}_{\mathrm{x}} / \mathrm{SO}_{2} ;$ boiler efficiency; fly ash; cement characteristics; economic assessment 


\section{Introduction}

To achieve the goal of renewable energy resources taking up to $12 \%$ of the total energy consumption in 2010, the European Union exploited approximately 1.3 billion tons of biomass [1], which will increase to 1.5-1.8 billion tons in 2030 [2]. Among that amount agro/forestry residues play a dominant role. Moreover, according to the "Mid-long Term Development Plan for Renewable Energy, China", the annual output of agro/forestry residues in China is about 1.5 billion tons, and 0.6 billion tons can be used for power generation, which equals to 0.35 billion tons of coal equivalent. The installed agro/forestry residue power capacity will reach $2.4 \times 10^{4} \mathrm{MW}$, accounting for $2.4 \%$ of the total power installed capacity by 2020 [3]. To date, more than 130 dedicated agro/forestry residue power plants have been built in China, but ash-related problems, especially fouling and slagging, resulting in lower heat transfer and unscheduled shutdowns of the furnaces, significantly restrict further promotion of the technology [4-7].

Co-firing in existing coal-fired boilers has been widely implemented in Europe and USA as a promising biomass utilization approach [8]. Most of the newly built coal power plants in Europe have a requirement for 10-20 cal\% co-firing capability [9]. Biomass co-firing can not only eliminate or reduce the slagging that inevitably occurs in dedicated biomass-fired furnaces [4,9-12], but also meet the needs of utilization and exploitation of renewable energy, especially agro/forestry residues. In addition, it can reduce greenhouse gas emissions and partially replace fossil fuels that cause serious environmental problems and are facing depletion in the near future.

It is well known that the ash of agro/forestry residues contains large amounts of alkaline salts [13,14], such as $\mathrm{KCl}$, which can capture sulfur during combustion and reduce $\mathrm{SO}_{2}$ emissions $[15,16]$. Meanwhile, the $\mathrm{HCl}$ generated by the sulphatization of $\mathrm{KCl}$ can be trapped by $\mathrm{CaO}$ quickly [17]. High concentration of volatile hydrocarbons from agro/forestry residues can react with $\mathrm{NO}_{\mathrm{x}}[18,19]$, thus, co-firing favors low $\mathrm{NO}_{\mathrm{x}}$ and $\mathrm{SO}_{2}$ emissions.

Otherwise, coal consumption of co-firing in a large Pulverized Coal (PC) furnace $(\sim 330 \mathrm{~g} / \mathrm{kWh}$ with modest co-firing ratio) is basically half of that of a dedicated biomass firing furnace $(\sim 630 \mathrm{~g} / \mathrm{kWh}$ in a grate furnace) with a thermal efficiency of around 50\% [20]. According to the assessment of the US DOE National Renewable Energy Laboratory (NREL) [21], the power generation efficiency of biomass co-firing remains unchanged or decreases slightly, and the efficiency can be maintained at $33 \%-37 \%$, even with an elevated co-firing ratio of $15 \mathrm{cal} \%$. Therefore, co-firing can utilize the higher boiler efficiency of large PC furnaces.

Savolainen [10] implemented co-firing testing with varied sawdust/coal ratios in a $315 \mathrm{MW} \mathrm{PC}$ furnace during 1999 to 2000, and the results showed that co-milling co-firing did not cause slagging and could reduce $\mathrm{SO}_{2}$ emissions. Unfortunately, when the co-firing ratio was increased to 2.5 cal\%, milling deteriorated, which resulted in increased unburned carbon in the fly ash and decreased boiler efficiency. Recently, our group had accomplished a varied proportion biomass pellet co-firing experiment in a $300 \mathrm{MW}$ PC furnace without any additional investments or retrofits. Biomass pellets were injected into the top burner system after grinding in existing roller mills with up to $16.1 \mathrm{cal} \%$ co-firing ratio [19]. Results showed that $\mathrm{NO}_{\mathrm{x}}$ emissions decreased with elevated biomass co-firing ratio, and co-firing did not affect the quality of the fly ash for use in the cement industry. It should be noted that ASTM C618 permits the use of coal fly ash of as a cement alternative, but 
biomass ash is forbidden [21,22], while the revised EN-450 (European technical standard for the use of coal fly ash for concrete) allows the fly ash of clean wood to be used for concrete, even with a co-firing ratio of up to $50 \mathrm{wt} \%$ [23]. According to the statistics of the American Coal Ash Association (ACCA) [24], more than half of the exploited coal fly ash is used as a cement raw material, concrete additive and blend, and a portion is used as fill materials and in plant nutrition.

Figure 1 is a detailed illustration of biomass dedicated firing and co-firing. Currently, biomass combustion technologies can be divided into dedicated biomass firing (in CFB furnaces and grate furnaces) and co-firing (in CFB and PC furnaces) [25,26]. The co-firing technologies in PC furnaces can be further classified into injection co-firing, co-milling co-firing, pre-gasification co-firing and parallel co-firing [25]. Compared with dedicated biomass firing, co-firing has lower investment, higher efficiency and lower emissions [27,28]. Co-milling co-firing, with the least investment, is favorable for low proportion biomass co-firing, but mill capacity limits the co-firing ratio [28]; Injection co-firing needs to be coupled with a dedicated biomass combustion and logistics system which results in higher investment, but the co-firing ratio can be improved; Both pre-gasification and parallel co-firing increase the biomass co-firing ratio significantly, even up to $100 \%$ biomass, but both need the construction of two systems (combustion or gasification) with exorbitant costs [29], so the co-milling co-firing and injection co-firing are in wide application now.

In theory, biomass co-firing (injection co-firing and co-milling co-firing) not only consumes agro/forestry residues, reduces pollution emissions and eliminates alkali slagging, but also takes advantage of the high efficiency of the large PC furnace [29]. Wang et al. [19] have pointed out that the boiler efficiency decreased by $0.19 \%-0.52 \%$ with a co-firing ratio from $9.68 \mathrm{wt} \%(6.53 \mathrm{cal} \%)$ to $22.7 \mathrm{wt} \%$ (16.1 cal\%). Similar results were reported in Plant Hammond, and the boiler efficiency decreased slightly with co-firing ratios of 9.7-13.5 wt\% [30]. Unfortunately, comprehensive and in-depth technical research on co-firing in commercial PC furnaces is not widely reported, and economic assessments of co-firing compared with dedicated biomass firing are also scarce.

Therefore, both technical and economic assessments of agro/forestry residues co-firing in a $300 \mathrm{MW}$ commercial PC furnace are conducted, and an advanced co-firing model possessing lower investment, lower pollution emissions, lower coal consumption, lower operating risk and higher boiler efficiency in comparison with dedicated firing and existing co-firing models is proposed. The new co-firing model used to consume agro/forestry residues is proposed first. Then, the technical assessment of the co-firing model is conducted on the basis of experimental study in a $300 \mathrm{MW}$ PC furnace, including milling energy consumption, environment impact $\left(\mathrm{CO}_{2}, \mathrm{NO}_{\mathrm{x}}\right.$ and $\mathrm{SO}_{2}$ emissions), fly ash reuse and boiler efficiency. Finally, an economic assessment is performed by the discounted cash flow (DCF) technique in comparison with dedicated biomass firing in grate furnace. 
Figure 1. Illustration on biomass firing and co-firing technologies.

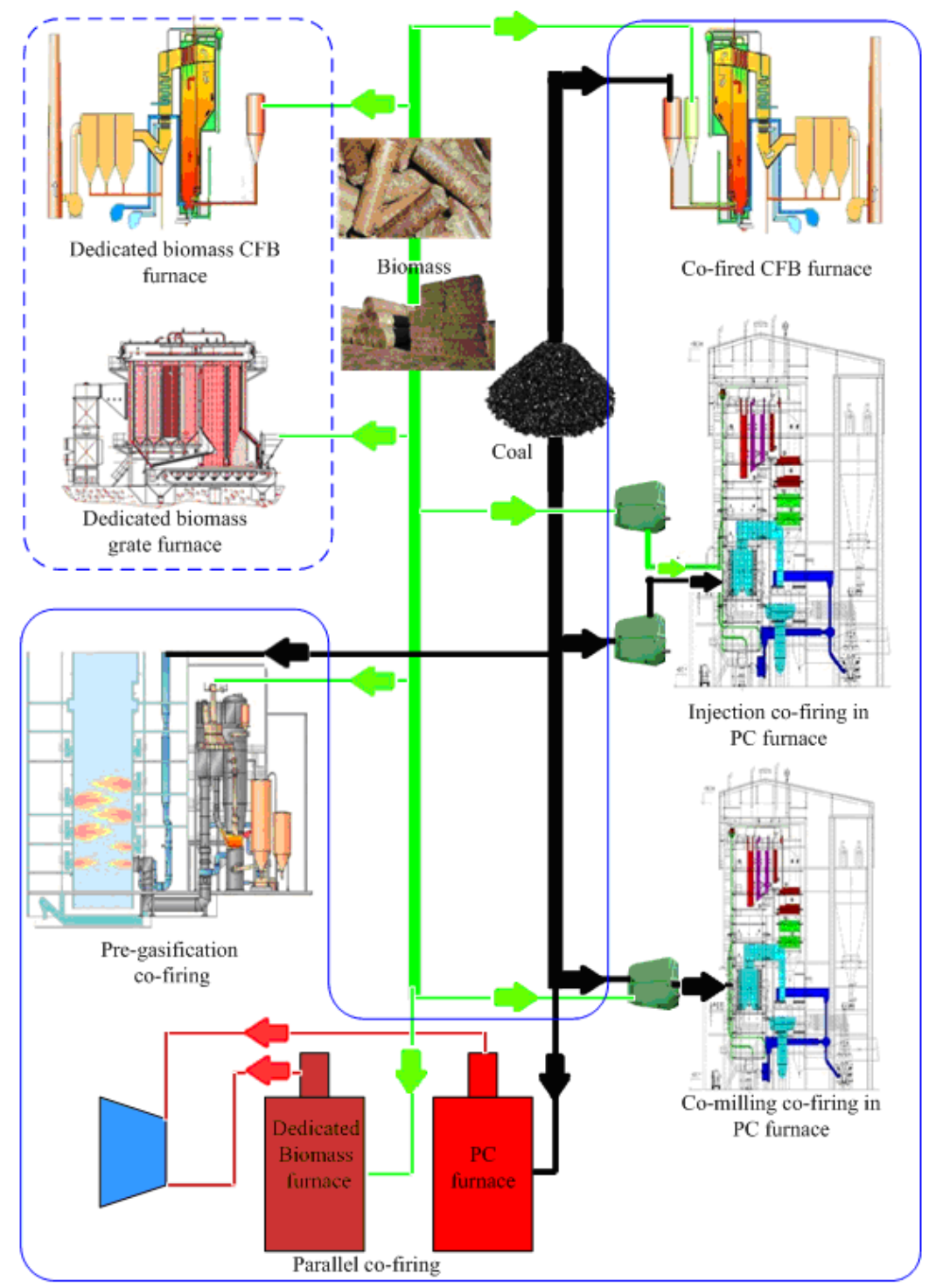

\section{Proposed Co-Firing Model}

As illustrated in Figure 2, the new co-firing model proposed here is more dependent on injection co-firing combined with co-milling co-firing. Firstly, various agro/forestry residues are collected and pretreated by a crusher and molding machine; secondly, the crush and pellet mixtures are transported to power plants; thirdly, blends of coal and the pellets/shreds of agro/forestry residues are injected into a specific burner system (top or bottom burner system) after co-milling, and the other burner systems are fed with pure coal. The agro/forestry residues are injected into only one burner system like injection co-firing, while they are mixed and co-milled with coal before injection like co-milling co-firing, so the co-firing model is a combination of injection co-firing and co-milling co-firing. In an injection co-firing furnace, pure biomass is injected into the specific burner system after milling, while in a co-milling co-firing furnace, biomass and coal mixture are injected into every burner system after co-milling. 
Figure 2. The proposed co-firing model of agro/forestry residues and coal.

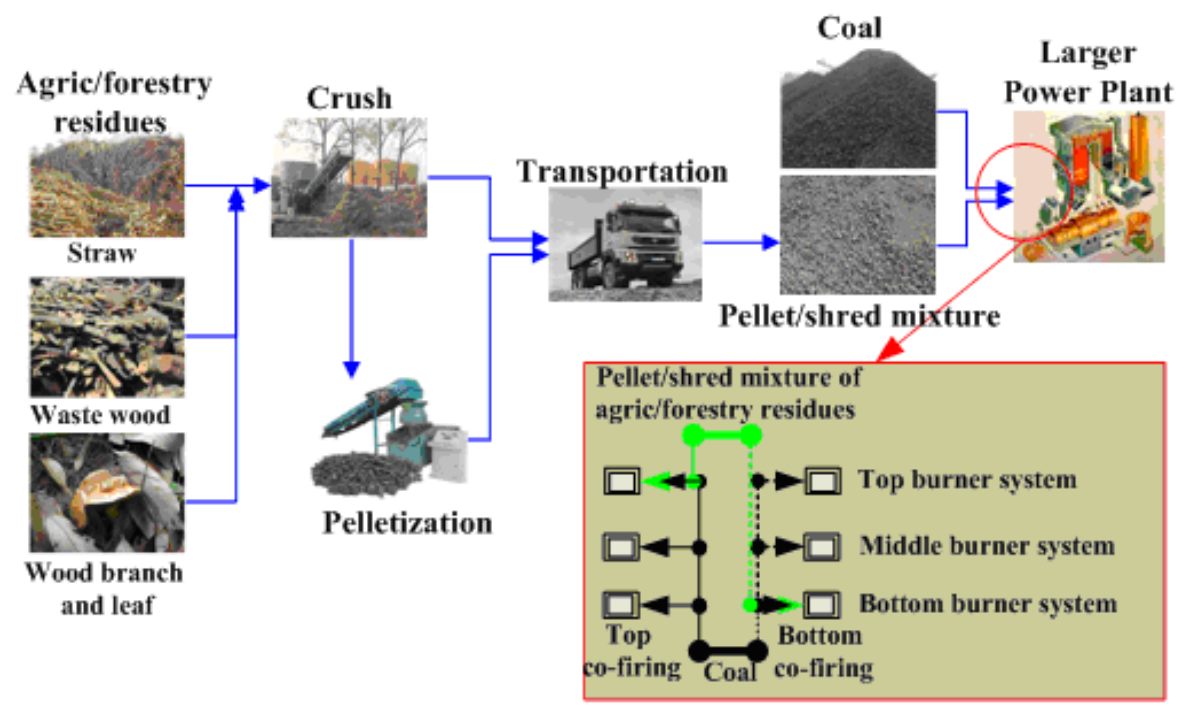

The advantages of the new co-firing model include:

1. compared with dedicated agro/forestry residues firing, it possesses lower investment with immediate benefits, lower pollution emissions, lower coal consumption and higher boiler efficiency, in addition to eliminating slagging and reducing the dependence on agro/forestry residues which are seasonal;

2. in comparison with injection co-firing, it does not need the construction of specific logistics systems and saves investment;

3. compared with co-milling co-firing, agro/forestry residues are only injected into one burner system, rather than into all burner systems, which reduces the probability of shutdowns caused by the blockage of the mills due to the uneven milling properties of agro/forestry residues;

4. co-firing by top or bottom burner system gives increased boiler efficiency in comparison with dedicated PC combustion. Corresponding explanations will be presented in Section 3.4.

\section{Technical Assessment}

Our technical assessment mainly focuses on milling energy consumption, environment impact, fly ash reuse and boiler efficiency, which are the concerns of the policymaker, power plant manager and environmentalist, respectively. The co-firing tests were conducted in a $300 \mathrm{MW}$ PC furnace, which contains six layers of burner systems named A-F in turn from bottom to top of the furnace; a detailed description can be seen in a previous paper [19]. Here, as shown in Figure 3, four conditions were tested: agro/forestry residues co-firing by burner systems B, D and F separately, and 100\% PC condition.

Throughout the experiment, the agro/forestry residue feed rate was about $7.2 \mathrm{t} / \mathrm{h}(5.2 \mathrm{wt} \%$, $3.2 \mathrm{cal} \%$ ). In order to maintain good flowability, the PC with a feed rate of $10.8 \mathrm{t} / \mathrm{h}$ was blended into the agro/forestry residues. When co-firing with burner F, $7.2 \mathrm{t} / \mathrm{h}$ of agro/forestry residues and $10.8 \mathrm{t} / \mathrm{h}$ of PC are injected into the furnace by burner $\mathrm{F}$ together, and the other burners, including $\mathrm{A}-\mathrm{E}$, are injected with PC, so the co-firing technology can be equivalent to a more dependent injection co-firing combined with co-milling co-firing. Pellets and shreds of agro/forestry residues account for 
approximately 50\% separately. Excessive decrease of the pellets ratio will result in mill blockage. Agro/forestry residue pellets are cylinders with a length of $\sim 65 \mathrm{~mm}$, diameter of $\sim 34 \mathrm{~mm}$ and density of $\sim 1.2 \mathrm{~g} \cdot \mathrm{cm}^{-3}$. The ultimate and proximate analyses of the fuels are shown in Table 1 . It can be seen that compared with coal, the agro/forestry residues have higher volatile and chlorine contents, and lower carbon content and heating value.

Figure 3. Schematic illustration of co-firing conditions.

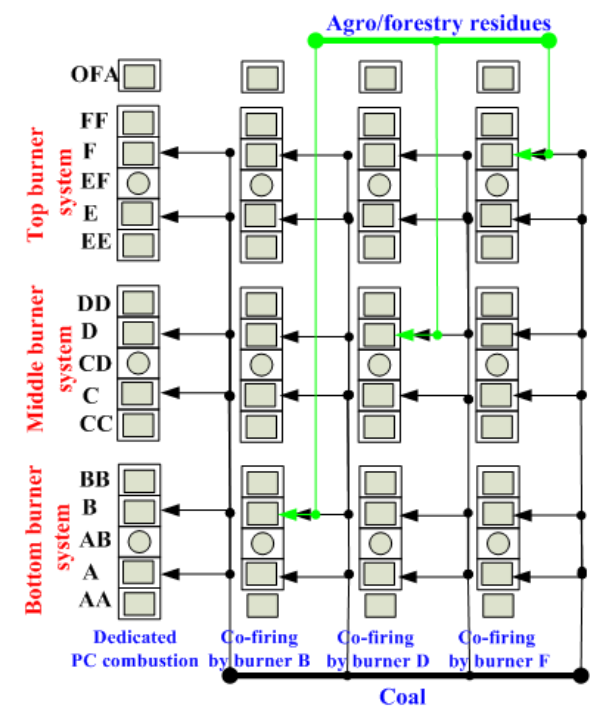

Table 1. Proximate analysis and ultimate analysis of fuels (ad: Air dried basis; ar: As received basis).

\begin{tabular}{cccc}
\hline Component & & Coal & Agro/forestry residues \\
\hline & $\mathrm{M}_{\mathrm{ad}}$ & 5.86 & 5.4 \\
\cline { 2 - 4 } & $\mathrm{A}_{\mathrm{ad}}$ & 20.81 & 8.09 \\
\cline { 2 - 4 } & $\mathrm{V}_{\mathrm{ad}}$ & 27.93 & 69.44 \\
\cline { 2 - 4 } & $\mathrm{FC}_{\mathrm{ad}}$ & 45.4 & 17.07 \\
\hline \multirow{5}{*}{ Proximate analysis/wt\% } & $\mathrm{C}_{\mathrm{ad}}$ & 58.9 & 41.88 \\
\cline { 2 - 4 } & $\mathrm{H}_{\mathrm{ad}}$ & 3.54 & 3.63 \\
\cline { 2 - 4 } & $\mathrm{O}_{\mathrm{ad}}$ & 9.61 & 39.47 \\
\cline { 2 - 4 } & $\mathrm{N}_{\mathrm{ad}}$ & 0.77 & 1.00 \\
\cline { 2 - 4 } & $\mathrm{S}_{\mathrm{t}, \mathrm{ad}}$ & 0.51 & 0.27 \\
\cline { 2 - 4 } & $\mathrm{Cl}_{\mathrm{ad}}$ & 0.02 & 0.31 \\
\hline Heat value/MJ/kg & $\mathrm{Q}_{\mathrm{net}, \mathrm{ar}}$ & 22.22 & 13.33 \\
\hline
\end{tabular}

In the experiments, the exhaust gas temperature was recorded directly from the DCS system; An isokinetic sampling method was applied for fuel powder samples and fly ash samples, and slag was sampled each $0.5 \mathrm{~h} ; \mathrm{O}_{2}, \mathrm{SO}_{2}$ and $\mathrm{NO}_{\mathrm{x}}$ were measured by a gas analyzer (Testo 350, Testo Ltd. Lenzkirch, Germany) in the outlet of the horizontal flue. The fly ash accumulated in the dust collector was cleared when each condition was operated for more than $0.5 \mathrm{~h}$ at first, and then $20-30 \mathrm{~kg}$ fly ash deposited in the dust collector were sampled before the end of each test condition for the cement properties testing. 


\subsection{Mill Performance}

Milling energy consumption is an important factor considered by policymakers and power plant managers. The energy consumption is calculated in detail as follows:

1. according to the site statistics, the total energy consumptions of crush and pelletization are $80.9 \mathrm{~kW}$ for the agro/forestry residues with a production of $7.2 \mathrm{t} / \mathrm{h}$;

2. the current of the agro/forestry residues mill is $37 \mathrm{~A}$, and voltage is $6 \mathrm{kV}$, so the energy consumption of agro/forestry residues accounts for: $(6 \mathrm{kV} \times 37 \mathrm{~A}-6 \mathrm{kV} \times 37 \mathrm{~A} \times 10.8 / 24) / 7.2 \mathrm{t} / \mathrm{h}=17.0 \mathrm{kWh} / \mathrm{t}$;

3. total energy consumption: $(17.0 \mathrm{kWh} / \mathrm{t} \times 7.2 \mathrm{t} / \mathrm{h}+80.9 \mathrm{~kW}) / 7.2 \mathrm{t} / \mathrm{h}=28.2 \mathrm{kWh} / \mathrm{t}$.

Table 2 is a summary of the milling energy consumptions of hammer mill for four biomasses with different moisture contents [31]. Considering the energy consumption and fuel size together, milling the agro/forestry residues pellets/shred mixture with a low speed roller mill is a more economical choice. As shown in Figure 4, 75\% of particles measured with LS230 laser particle size were smaller than $200 \mu \mathrm{m}$ and $97 \%$ were smaller than $850 \mu \mathrm{m}$.

Table 2. Milling energy consumption of hammer mill for different biomass [31].

\begin{tabular}{ccccc}
\hline Biomass & $\begin{array}{c}\text { Moisture/wt } \\
\text { \% }\end{array}$ & $\begin{array}{c}\text { Mean } \\
\text { diameter/mm }\end{array}$ & $\begin{array}{c}\text { Up-limitation of } \\
\text { diameter/mm }\end{array}$ & $\begin{array}{c}\text { Energy consumption } \\
/ \mathbf{k W h} / \mathbf{t}\end{array}$ \\
\hline Wheat straw & 8.3 & 7.67 & $3.2 / 1.6 / 0.8$ & $11.36 / 37.01 / 51.55$ \\
Wheat straw & 12.1 & 7.67 & $3.2 / 1.6 / 0.8$ & $24.66 / 43.56 / 45.32$ \\
Barley straw & 6.9 & 20.52 & $3.2 / 1.6 / 0.8$ & $13.79 / 37.91 / 53.00$ \\
Barley straw & 12.0 & 20.52 & $1.6 / 0.8$ & $27.09 / 99.49$ \\
Corn stalk & 6.2 & 12.48 & $3.2 / 1.6 / 0.8$ & $6.96 / 14.79 / 22.07$ \\
Corn stalk & 12.0 & 12.48 & $3.2 / 1.6 / 0.8$ & $11.04 / 19.84 / 34.30$ \\
Switchgrass & 8.0 & 7.15 & $3.2 / 1.6 / 0.8$ & $23.84 / 51.76 / 62.55$ \\
Switchgrass & 12.0 & 7.15 & $3.2 / 1.6 / 0.8$ & $27.63 / 58.47 / 56.57$ \\
\hline
\end{tabular}

Figure 4. Size distributions of raw materials.

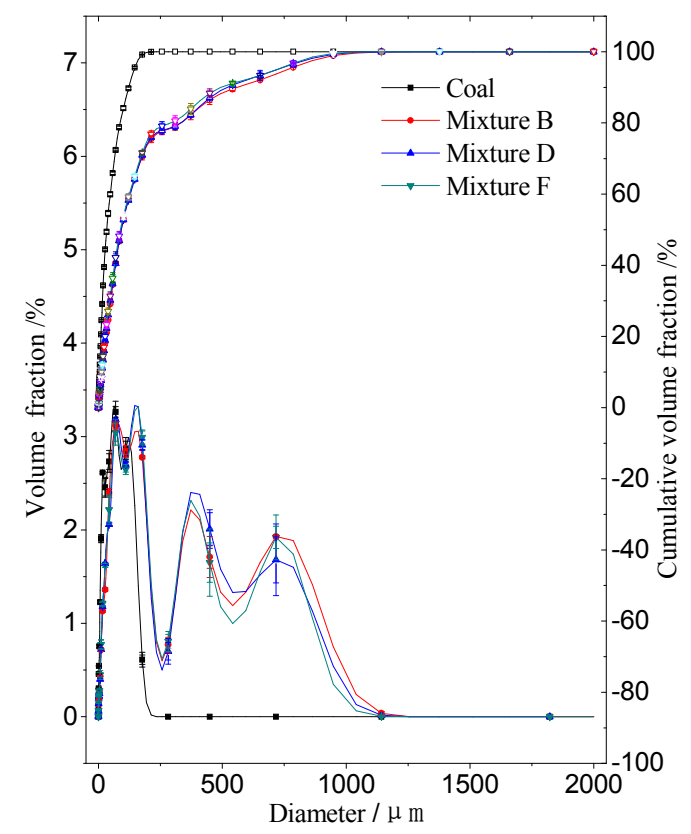


Therefore, low speed roller mills existing in large scale commercial PC power plants can comminute coal and agro/forestry residues pellets/shred mixtures technically and economically.

\subsection{Environmental Feedback}

For the reasons of the wide application of agro/forestry residues, in addition to the huge generation and accumulation of various agro/forestry residues as well as the depletion of the fossil fuels, the high environmental benefit is another driving force.

Figure 5 shows the statistical average values of $\mathrm{SO}_{2}$ and $\mathrm{NO}_{\mathrm{x}}$ emissions. Both co-firing and co-firing injection position did not have a significant effect on $\mathrm{SO}_{2}$ and $\mathrm{NO}_{\mathrm{x}}$ emissions, which may be due to the low co-firing ratio. Otherwise, co-firing basically did not affect the temperature distribution in the furnace, so co-firing had no effect on thermal- $\mathrm{NO}_{\mathrm{x}}$.

Figure 5. Statistics of $\mathrm{SO}_{2}$ and $\mathrm{NO} x$ emissions.

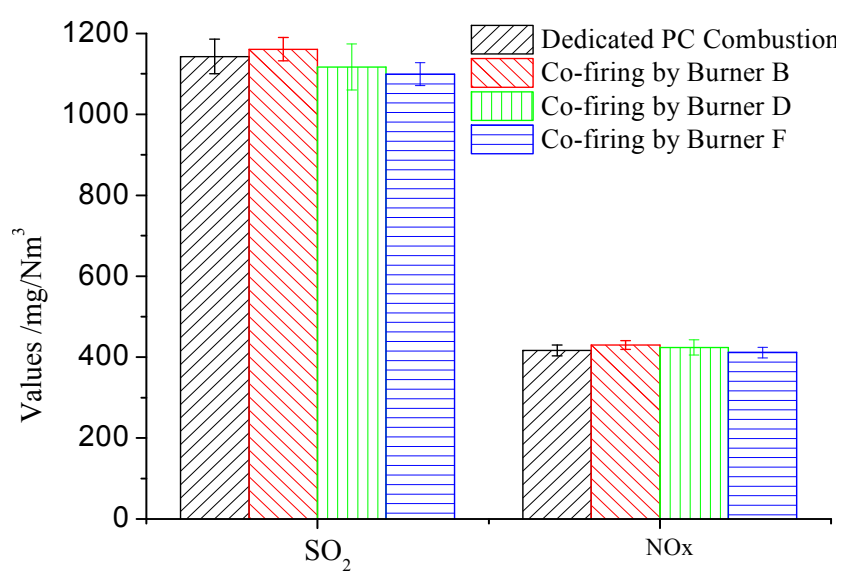

When considering the effect of higher levels of volatile hydrocarbons and the lower heat value of agro/forestry residues which can reduce $\mathrm{NO}_{\mathrm{x}}$ generation $[18,19]$, and higher levels of alkali metals which can capture $\mathrm{SO}_{2}$ [32], co-firing can theoretically decrease $\mathrm{NO}_{\mathrm{x}}$ and $\mathrm{SO}_{2}$ emissions. With the co-firing ratio used here $(7.2 \mathrm{t} / \mathrm{h}, 5.2 \mathrm{wt} \%, 3.2 \mathrm{cal} \%)$, and assuming $5000 \mathrm{~h}$ of annual operating time, it can replace $2.2 \times 10^{4}$ tons of coal and reduce $\mathrm{CO}_{2} 7.9 \times 10^{4}$ tons, so agro/forestry residues possess higher environmental benefits.

\subsection{Fly Ash Reuse}

The cement characteristics decide whether the fly ash can be used as cement, concrete additive and blend, and the chemical elements content and compounds determine whether it can be used as fill material and in plant nutrition, so the cement characteristics and chemical properties of the fly ash produced by co-firing were analyzed.

\subsubsection{Cement Characteristics}

The cement characteristics of the fly ash or the possibility of using the fly ash as a cement alternative are tested according to Chinese Standard GB/T1596-2005, GSB 14-1510, and GB/T17671-1999. The 
key parameters used in the concrete industry, including condensation starting/ending time, expansion, water demand ratio, compressive and flexural strengths at 7/28/90 days, and activity index, are tested. The declarations of corresponding parameters are as follows:

- condensation starting time: The time that the cement slurry starts to lose plasticity;

- condensation ending time: The time that the cement slurry loses plasticity completely;

- expansion: The volume change in the hardening process of cement;

- water demand ratio: The water demand ratio of tested sample and standard sample when fluidity is $130 \mathrm{~mm}-140 \mathrm{~mm}$;

- compressive strength: The maximum compression force that the tested mortar can withstand;

- flexural strength: The maximum bending force that the tested mortar can withstand;

- activity index: The ratio of the compressive strength of the tested mortar and the standard contrast mortar (28 days).

As seen from Table 3 where PC represents dedicated PC combustion, Burner B, D and F mean co-firing by burner B, D and F, with or without co-firing the condensation starting/ending times, expansion and water demand ratio satisfied GB/T1596-2005, while compressive and flexural strengths as well as activity index were lower than the indicators of GB/T1596-2005, especially the compressive strength and activity index. Meanwhile, it should be noted that the compressive and flexural strengths and activity index of the fly ash of co-firing were more dependent on the corresponding parameters of the coal fly ash. Agro/forestry residues co-firing only caused an approximately $6 \%$ decline in compressive strength and activity index (28 days), and the influence is minor. Otherwise, according to the tested results of previous co-firing experiments by burner F with different co-firing ratios [19], co-firing also resulted in decreased compressive and flexural strengths and activity index, even though that the testing results satisfy GB/T1596-2005, and the compressive strength and activity index decreased by $5 \%-6 \%$ with co-firing ratios of $9.68 \mathrm{wt} \%$ and $22.7 \mathrm{wt} \%$.

Table 3. Test results of key parameters for cement characteristics of fly ash.

\begin{tabular}{cccccccc}
\hline Parameters & Unit & PC & Burner B & Burner D & Burner F & Contrast & Criterion \\
\hline Condensation starting time & $\mathrm{min}$ & 234 & 214 & 240 & 225 & $/$ & $>45$ \\
Condensation ending time & $\mathrm{h}$ & 4.6 & 4.38 & 4.47 & 4.55 & $/$ & $<10$ \\
Expansion & $\mathrm{mm}$ & 1.9 & 1.1 & 1.9 & 1.6 & $/$ & $<5$ \\
Water demand ratio & $\%$ & 88.8 & 93.6 & 91.2 & 94.4 & $/$ & $<95$ \\
Flexural strength (7 days) & $\mathrm{MPa}$ & 4.3 & 4.4 & 4.3 & 4.4 & 6.2 & $/$ \\
Compressive strength (7 days) & $\mathrm{MPa}$ & 17.5 & 16.6 & 17.1 & 16.4 & 27.3 & $/$ \\
Flexural strength (28 days) & $\mathrm{MPa}$ & 5.9 & 5.7 & 5.2 & 5.4 & 7.2 & $\geq 5.5$ \\
Compressive strength (28 days) & $\mathrm{MPa}$ & 26.2 & 23.8 & 24.9 & 25.1 & 44.6 & $\geq 32.5$ \\
Flexural strength (90 days) & $\mathrm{MPa}$ & 7.2 & 6.7 & 7.2 & 6.9 & 9.1 & $/$ \\
Compressive strength (90 days) & $\mathrm{MPa}$ & 38.9 & 37.2 & 37.5 & 37.8 & 50.1 & $/$ \\
Activity index & $\%$ & 58.7 & 53.4 & 55.8 & 56.3 & 100 & $\geq 70$ \\
\hline
\end{tabular}

Therefore, the cement characteristics of the fly ash produced by agro/forestry residue co-firing were more dependent on the primary fuel-coal, and a modest co-firing ratio $(<20 \mathrm{wt} \%)$ does not significantly affect the fly ash use as a cement alternative. 


\subsubsection{Chemical Properties}

Table 4 shows the element composition of the fly ashes analyzed by XRF. It can be seen that the variations caused by co-firing were slight, and both co-firing and co-firing position did not have significant effect on the elemental distributions of the fly ash. The main elements were $\mathrm{Si}, \mathrm{Al}, \mathrm{Ca}$, Fe and $\mathrm{K}$.

Table 4. XRF (X-ray fluorescence) analyzed results of fly ash.

\begin{tabular}{cccccccccccc}
\hline Condition & Si & Al & Fe & Ca & Mg & Ti & K & Na & S & P & O \\
\hline PC & 23.5 & 13.1 & 3.3 & 3.1 & 0.6 & 0.7 & 2.8 & 0.8 & 0.2 & 0.0 & 51.2 \\
Co-firing by Burner B & 23.0 & 14.3 & 3.4 & 3.0 & 0.6 & 0.7 & 2.4 & 0.7 & 0.1 & 0.1 & 51.4 \\
Co-firing by Burner D & 22.7 & 11.4 & 2.8 & 3.2 & 0.6 & 0.5 & 2.8 & 0.9 & 0.1 & 0.0 & 54.7 \\
Co-firing by Burner F & 24.1 & 13.0 & 3.7 & 3.3 & 0.8 & 0.7 & 3.0 & 0.8 & 0.1 & 0.1 & 50.4 \\
Average & 23.3 & 12.9 & 3.3 & 3.2 & 0.7 & 0.6 & 2.7 & 0.8 & 0.1 & 0.1 & 52.2 \\
\hline
\end{tabular}

Similarly, as seen from Figure 6, due to the low co-firing ratio, co-firing and co-firing position also did not have any significant effect on the components of the fly ash analyzed by XRD. The main components of the fly ash were quartz and multi-mullites. Making things convenient for comparison, Figure $6 \mathrm{a}$ is the amplified illustration of Figure $6 \mathrm{~b}$.

Figure 6. XRD (X-ray diffraction) analyzed results of fly ash. (a) Amplified illustration; (b) Original illustration.
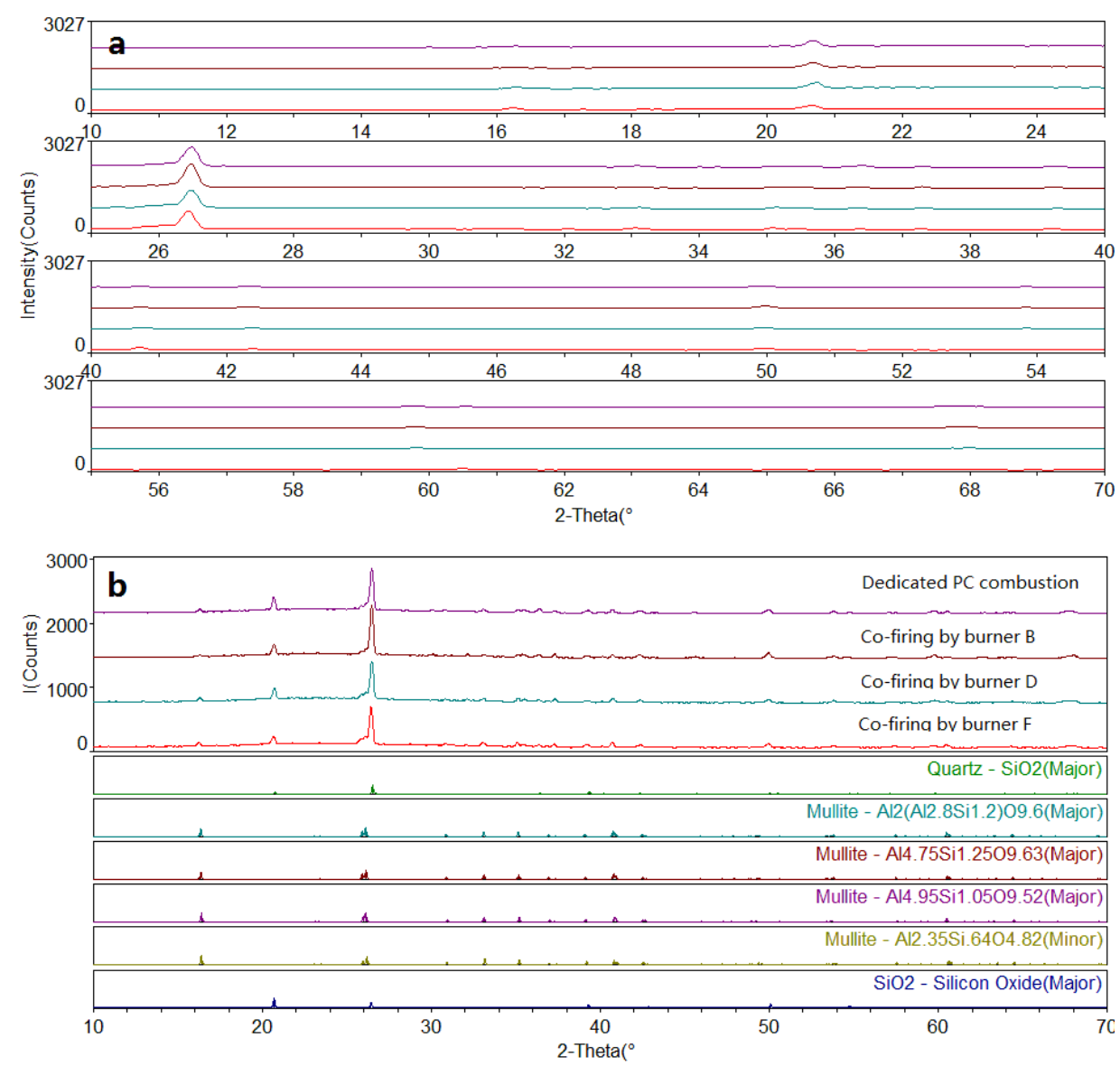


\subsection{Boiler Efficiency}

To environmentalists and policymakers, maybe environmental protection and energy savings are what they are concerned about, while for a power plant manager, economy is the preferred, and among that, boiler efficiency is an important factor. If the boiler efficiency decreases $0.1 \%$ for a $300 \mathrm{MW}$ unit, the coal consumption will increases about 900 tec/y, which will cost $\$ 110,000$. The boiler efficiency is therefore considered here.

Table 5 (PC represents dedicated PC combustion; Burner B, D and F mean co-firing by burner B, D and F) shows the summary of the boiler efficiencies calculated by the anti-balance method which has been widely used for boiler efficiency calculations due to its high precision. It can be seen that co-firing can increase the boiler efficiency by $0.05 \%-0.31 \%$ in comparison with dedicated PC combustion. This may be due to the easy ignition and burnout properties of agro/forestry residues [33]. Otherwise, co-firing by bottom and top burner systems presented obviously higher boiler efficiency in comparison with co-firing by the middle burner system, basically around $0.2 \%$. When co-firing with bottom burner $\mathrm{B}$, the unburned carbon in the slag decreases due to the timely ignition of the agro/forestry residues, which promote the propagation of flames. When co-firing with top burner $\mathrm{F}$, the unburned carbon in the fly ash decreases due to the easier burnout of the agro/forestry residues, unlike coal, which needs longer residence times.

Table 5. Summary of boiler efficiencies.

\begin{tabular}{cccccc}
\hline \multirow{2}{*}{ Item } & \multirow{2}{*}{ Unit } & \multicolumn{4}{c}{ Average Value } \\
\cline { 3 - 6 } & & PC & Burner B & Burner D & Burner F \\
\hline Unburned carbon in slag & $\%$ & 1.79 & 1.15 & 1.44 & 1.76 \\
Unburned carbon in fly ash & $\%$ & 0.88 & 0.46 & 0.46 & 0.14 \\
Flue gas oxygen content & $\%$ & 6.85 & 6.02 & 5.7 & 6.92 \\
Exhaust gas temperature & ${ }^{\circ} \mathrm{C}$ & 130.8 & 130.72 & 134.24 & 126.72 \\
Boiler efficiency & $\%$ & 93.38 & 93.59 & 93.43 & 93.69 \\
Efficiency change & $\%$ & 0 & 0.21 & 0.05 & 0.31 \\
\hline
\end{tabular}

The data presented in the table are average values, and the relative deviations of the data are all lower than 3\% according to the original measured data. Our previous study shows that with increased co-firing ratios from $9.68 \mathrm{wt} \%(6.53 \mathrm{cal} \%)$ to $22.7 \mathrm{wt} \%(16.1 \mathrm{cal} \%)$, the boiler efficiency decreases by $0.19 \%-0.52 \%$ [19]. Similar results were reported in Plant Hammond, and the boiler efficiency decreases slightly with co-firing ratios of 9.7-13.5 wt $\%$ [30].

Therefore, it seems that a high co-firing ratio $(>10 \mathrm{wt} \%)$ results in decreasing boiler efficiency, while a low co-firing ratio $(<5 \mathrm{wt} \%)$ can raise boiler efficiency. This can be explained by the competition mechanism as follows: due to the easy ignition and burnout properties of agro/forestry residues, co-firing of agro/forestry residue results in decreased unburned carbon in fly ash and slag, and further the boiler efficiency increases, while a high agro/forestry residue co-firing ratio decreases the whole furnace temperature due to the lower primary air temperature of the agro/forestry residues (in case of self-ignition) and lower burning temperature of the agro/forestry residues (lower heating value) in comparison with coal, thus the unburned carbon in fly ash increases and boiler efficiency decreases. Of course, with a low biomass co-firing ratio, the furnace temperature also decreases. 
However, compared with the increase of the boiler efficiency caused by the easy ignition and burnout of biomass, the decrease of boiler efficiency caused by the low burning temperature is lesser. Similarly, with a high biomass co-firing ratio, the increase of boiler efficiency caused by the easy ignition and burnout properties of biomass is inferior to the decrease of the boiler efficiency caused by the low burning temperature. Therefore, the competition between the easy ignition/burnout properties and low burning temperature of biomass results in increased boiler efficiency with a low biomass co-firing ratio and decreased boiler efficiency with a high biomass co-firing ratio in comparison with dedicated PC combustion.

Therefore, the existing moderate speed roller mills found in large scale commercial PC furnaces can comminute coal and agro/forestry residues pellet/shred mixtures technically, and co-firing also can reduce $\mathrm{CO}_{2}, \mathrm{NO}_{\mathrm{x}}$ and $\mathrm{SO}_{2}$ emissions with slight influences on the properties of fly ash and boiler efficiency. With a proper co-firing ratio, the boiler efficiency increases, thus, agro/forestry residue co-firing in a large scale commercial PC furnace is technically feasible.

\section{Economic Assessment}

\subsection{Discounted Cash Flow (DCF) Technique}

The economical assessment of the co-firing model described above in comparison with dedicated biomass firing in a grate furnace is performed by DCF, mainly considering net present value (NPV), payback period $\left(\mathrm{n}_{\mathrm{p}}\right)$ and internal rate of return (IRR).

NPV is an indicator that how much does an investment or project make. Between two mutually exclusive alternatives, the one yielding higher NPV should be selected. NPV is defined as the difference of income Pin and outgoing Pout (Equation 1), corresponding Pin and Pout are calculated according to Equation (2):

$$
\begin{gathered}
N P V=\text { Pin }- \text { Pout } \\
P=A_{0}\left[\frac{1}{(1+i)^{0}}\right]+A_{1}\left[\frac{1}{(1+i)^{1}}\right]+\cdots \\
+A_{n-1}\left[\frac{1}{(1+i)^{n-1}}\right]+A_{n}\left[\frac{1}{(1+i)^{n}}\right]
\end{gathered}
$$

where $P$ is the discounted present value of the future cash flow; $A_{n}$ is annual value at the end of each year; $i$ is interest rate, ignoring inflation; $I=3.25 \% ; n$ is time, year.

The term $n_{p}$, taken into account together with NPV, is the time required to recover the cost of the investment. Considering the time value of money, the formula is expressed as follows:

$$
0=-P_{\text {initial }}+\mathrm{NCF}\left(P / A, \mathrm{i}, \mathrm{n}_{\mathrm{p}}\right)
$$

where $P_{\text {initial }}$ is initial investment; NCF is net cash flow.

IRR is the discount rate that makes NPV equal to zero. Simply, when Equation $(1)=0$, the corresponding $i$ in Equation (2). Assuming both NPV and $\mathrm{n}_{\mathrm{p}}$ are equal among the various projects, the project with the highest IRR should be undertaken first. However, a project which has a higher IRR 
than an alternative may still be rejected if it does not meet with the expectations or targets set by the company/process management.

\subsection{Economic Comparison}

For agro/forestry residue dedicated firing and co-firing, the logistics total cost can be divided into eight aspects including fuel feedstock cost $\mathrm{Q}_{1}$; electricity consumption of pretreatment equipment $\mathrm{Q}_{2}$; labor cost of pretreatment $\mathrm{Q}_{3}$; transportation expenses cost $\mathrm{Q}_{4}$; venue rental $\mathrm{Q}_{5}$; equipment cost $\mathrm{Q}_{6}$; management fees $\mathrm{Q}_{7}$ and others $\mathrm{Q}_{8}$. The term $\mathrm{Q}_{2}$ contains the electricity consumption of agro/forestry residues crushing and pelletization. $\mathrm{Q}_{6}$ contains the purchase costs of forming machine, forming mold, crusher for the pretreatment of agro/forestry residues before burning in PC furnace and the construction costs of a dedicated firing power plant.

Note that: the co-firing ratio of agro/forestry residues is assumed as $10 \mathrm{wt} \%$ in the economic comparison, which basically equals to the annual consumption in a $12 \mathrm{MW}$ dedicated biomass firing grate furnace, $\sim 10^{4}$ tons; management fees $\mathrm{Q}_{7}$ accounts for $4 \%$ of the total costs, the plant life is assumed as 25 years; the total construction cost for the biomass dedicated firing power plant is 150 millions RMB; network power price is $0.3 \mathrm{RMB} / \mathrm{kWh}$ in China, but the network power price of biomass direct-fired power plant is $0.75 \mathrm{RMB} / \mathrm{kWh}$ due to the government subsidies. And d presents 2-24 in Table 6 which shows the calculation by DCF.

It can be seen from Table 6 that compared with co-firing, the agro/forestry residue dedicated firing is disadvantaged whether considering NPV, $\mathrm{n}_{\mathrm{p}}$ or IRR. Especially, without any government subsidies the dedicated firing of agro/forestry residues is in a serious deficit, NPV $<0$. Even considering the government subsidies, co-firing still has higher NPV and IRR, as well as lower $n_{p}$. NPV, IRR and $n_{p}$ of co-firing are 1.4, 4.6 and 0.21 times of those of dedicated firing in grate furnace, respectively.

Table 6. Summary of various parameters of dedicated biomass firing and co-firing.

\begin{tabular}{|c|c|c|c|c|}
\hline Parameters & Units & \multicolumn{2}{|c|}{ Directed firing } & Co-firing \\
\hline \multicolumn{5}{|c|}{ Outgoing } \\
\hline $\mathrm{Q}_{1}$ & $10^{6} \mathrm{RMB} / \mathrm{y}$ & \multicolumn{2}{|c|}{24} & 24 \\
\hline $\mathrm{Q}_{2}$ & $10^{6} \mathrm{RMB} / \mathrm{y}$ & \multicolumn{2}{|c|}{0} & 1.64 \\
\hline $\mathrm{Q}_{3}$ & $10^{6} \mathrm{RMB} / \mathrm{y}$ & \multicolumn{2}{|c|}{0} & 2.25 \\
\hline $\mathrm{Q}_{4}$ & $10^{6} \mathrm{RMB} / \mathrm{y}$ & \multicolumn{2}{|c|}{3.0} & 2.0 \\
\hline $\mathrm{Q}_{5}$ & $10^{6} \mathrm{RMB} / \mathrm{y}$ & \multicolumn{2}{|c|}{0} & 0.192 \\
\hline $\mathrm{Q}_{6}$ & $10^{6} \mathrm{RMB} / \mathrm{y}$ & \multicolumn{2}{|c|}{150} & 1.667 \\
\hline $\mathrm{Q}_{8}$ & $10^{6} \mathrm{RMB} / \mathrm{y}$ & \multicolumn{2}{|c|}{0.4} & 0.3 \\
\hline \multicolumn{5}{|c|}{ Income } \\
\hline Electricity price & $\mathrm{RMB} / \mathrm{kWh}$ & 0.30 & 0.75 & 0.3 \\
\hline \multicolumn{5}{|c|}{ DCF analysis results } \\
\hline$A_{1}$ & $10^{6} \mathrm{RMB}$ & 184.79 & 184.79 & 33.38 \\
\hline$A_{i}^{\mathrm{d}}$ & $10^{6} \mathrm{RMB}$ & -8.74 & 20.96 & 16.12 \\
\hline$A_{25}$ & $10^{6} \mathrm{RMB}$ & 19.8 & 49.5 & 49.5 \\
\hline NPV & $10^{6} \mathrm{RMB}$ & -320.03 & 183.03 & 254.59 \\
\hline $\mathrm{n}_{\mathrm{p}}$ & $\mathrm{y}$ & - & 10.56 & 2.18 \\
\hline IRR & $\%$ & - & 10.55 & 48.28 \\
\hline
\end{tabular}


In this section, only the cost before the agro/forestry residues are delivered into the furnace is considered, but the influence of boiler efficiency and burnout is ignored. Actually, both burnout and the boiler efficiency of agro/forestry residue dedicated firing in a grate furnace are clearly lower than those of co-firing in a large PC furnace. That results in the coal consumption of agro/forestry residue dedicated firing in a grate furnace being basically two times of that of co-firing in a large PC furnace. Thus, in comparison with dedicated firing, agro/forestry residue co-firing is more economic.

Seen from the technical and economic assessments, agro/forestry residue co-firing possesses higher economy, and co-firing by a bottom burner system and top burner system are more economical due to the higher boiler efficiency. Therefore, the model of the agro/forestry residues co-firing by a bottom burner system and top burner system, a combination of injection co-firing and co-milling co-firing, is proposed.

\section{Conclusions}

Co-firing tests showed that the moderate speed roller mills existing in power plants can comminute pelletized and shredded agro/forestry residues mixtures technically and economically. $\mathrm{NO}_{\mathrm{x}}$ and $\mathrm{SO}_{2}$ emissions remained unchanged in the experiment. Otherwise, XRF, XRD and cement characteristic analyses indicated that the chemical properties and cement characteristics of fly ashes produced by co-firing were more dependent on the fly ash properties of coal. Basically, with a modest co-firing ratio ( $<20 \mathrm{wt} \%$ ) both compressive strength and activity index decreased by approximate $6 \%$.

Moreover, our economic assessment shows that in comparison with biomass dedicated firing in a grate furnace, co-firing in a large PC furnace is more economic because of the higher net present value and internal rate of return as well as lower payback period. A $12 \mathrm{MW}$ agro/forestry residue grate furnace without government subsidies it is in serious deficit, and even with government subsidies, the net present value and internal rate of return are only 0.7 and 0.2 times of those of co-firing in a $300 \mathrm{MW}$ PC furnace respectively, and the payback period is 4.8 times longer.

Additionally, due to the competition between the easy ignition/burnout properties and low burning temperature of agro/forestry residues, co-firing with low co-firing ratios $(<5 \mathrm{wt} \%)$ increased boiler efficiency by $0.05 \%-0.31 \%$ in comparison with dedicated PC firing. The boiler efficiencies of co-firing in bottom and top burner systems were about $0.2 \%$ higher than that of co-firing in a middle burner system.

Therefore, a new co-firing model being more dependent on injection co-firing combined with co-milling/co-firing of agro/forestry residue pellets/shreds in a large PC furnace using the top or bottom burner systems is proposed. It not only can consume agro/forestry residues, ease the fossil fuel crisis, reduce the dependence on fuel and eliminate slagging occurred in biomass dedicated firing furnaces, but also results in higher economy and higher environmental benefits.

\section{Acknowledgments}

The present work was supported by China Postdoctoral Science Foundation funded project (2013M532046), and the Key Projects in the National Science \& Technology Pillar Program during the Twelfth Five-year Plan Period (No. 2011BAK06B04). Meanwhile, we are greatly grateful of The 
Second Power Plant of Baoji, Shaanxi Province, China, who provided the funds and the experimental facilities.

\section{Conflicts of Interest}

The authors declare no conflict of interest.

\section{References}

1. European Environment Agency. How much Biomass Can Europe Use without Harming the Environment; European Environment Agency: Copenhagen, Denmark, 2005.

2. European Commission (EC). Biomass Potential in Europel; European Commission: Brussels, Belgium, 2006.

3. National Development and Reform Commission. Mid-long term development plan for renewable energy. Renew. Energy Resour. 2007, 25, 1-5.

4. Niu, Y.Q.; Tan, H.Z.; Ma, L.; Pourkashanian, M.; Liu, Z.N.; Liu, Y.; Wang, X.B.; Liu, H.Y.; $\mathrm{Xu}, \mathrm{T} . \mathrm{M}$. Slagging characteristics on the superheaters of a $12 \mathrm{MW}$ biomass-fired boiler. Energy Fuels 2010, 24, 5222-5227.

5. Niu, Y.Q.; Tan, H.Z.; Wang, X.B.; Liu, Z.N.; Liu, Y.; Xu, T.M. Study on deposits on the surface, upstream, and downstream of bag filters in a $12 \mathrm{MW}$ biomass-fired boiler. Energy Fuels 2010, 24, 2127-2132.

6. Reichelt, J.; Pfrang-Stotz, G.; Bergfeldt, B.; Seifert, H.; Knapp, P. Formation of deposits on the surfaces of superheaters and economisers of MSW incinerator plants. Waste Manag. 2013, $33,43-51$.

7. Oh, H.; Annamalai, K.; Sweeten, J.M. Effects of ash fouling on heat transfer during combustion of cattle biomass in a small-scale boiler burner facility under unsteady transition conditions. Int. J. Energy Res. 2011, 35, 1236-1249.

8. Bridgeman, T.G.; Jones, J.M.; Williams, A.; Waldron, D.J. An investigation of the grindability of two torrefied energy crops. Fuel 2010, 89, 3911-3918.

9. Livingston, W.R. Biomass Ash and the Mixed Ashes from Co-Firing Biomass with Coal. In Proceedings of the IEA Clean Coal Workshop, Drax Power Station, London, UK, 25-26 January 2011.

10. Savolainen, K. Co-firing of biomass in coal-fired utility boilers. Appl. Energy 2003, 74, 369-381.

11. Baxter, L. Biomass-coal co-combustion: Opportunity for affordable renewable energy. Fuel 2005, $84,1295-1302$.

12. Shao, Y.; Wang, J.; Preto, F.; Zhu, J.; Xu, C. Ash deposition in biomass combustion or co-firing for power/heat generation. Energies 2012, 5, 5171-5189.

13. Niu, Y.Q.; Tan, H.Z.; Wang, X.B.; Liu, Z.N.; Liu, H.Y.; Liu, Y.; Xu, T.M. Study on fusion characteristics of biomass ash. Bioresour. Technol. 2010, 101, 9373-9381.

14. Niu, Y.; Du, W.; Tan, H.; Xu, W.; Liu, Y.; Xiong, Y.; Hui, S. Further study on biomass ash characteristics at elevated ashing temperatures: The evolution of $\mathrm{K}, \mathrm{Cl}, \mathrm{S}$ and the ash fusion characteristics. Bioresour. Technol. 2013, 129, 642-645. 
15. Pettersson, A.; Amand, L.E.; Steenari, B.M. Chemical fractionation for the characterisation of fly ashes from co-combustion of biofuels using different methods for alkali reduction. Fuel 2009, 88, $1758-1772$.

16. Sandberg, J.; Karlsson, C.; Fdhila, R.B. A 7 year long measurement period investigating the correlation of corrosion, deposit and fuel in a biomass fired circulated fluidized bed boiler. Appl. Energy 2011, 88, 99-110.

17. Bostrom, D.; Skoglund, N.; Grimm, A.; Boman, C.; Ohman, M.; Brostrom, M.; Backman, R. Ash transformation chemistry during combustion of biomass. Energy Fuels 2012, 26, 85-93.

18. Huang, Y.; McIlveen-Wright, D.; Rezvani, S.; Wang, Y.D.; Hewitt, N.; Williams, B.C. Biomass co-firing in a pressurized fluidized bed combustion (PFBC) combined cycle power plant: A techno-environmental assessment based on computational simulations. Fuel Process. Technol. 2006, 87, 927-934.

19. Wang, X.B.; Tan, H.Z.; Niu, Y.Q.; Pourkashanian, M.; Ma, L.; Chen, E.Q.; Liu, Y.; Liu, Z.N.; $\mathrm{Xu}, \mathrm{T} . \mathrm{M}$. Experimental investigation on biomass co-firing in a $300 \mathrm{MW}$ pulverized coal-fired utility furnace in China. Proc. Combust. Inst. 2011, 33, 2725-2733.

20. Tariq, A.S.; Purvis, M.R.I. NOx emissions and thermal efficiencies of small scale biomass-fuelled combustion plant with reference to process industries in a developing country. Int. J. Energy Res. 1996, 20, 41-55.

21. Biopower Factsheet-Biomass Cofiring: A Renewable Alternative for Utilities; National Renewable Energy Laboratory: Golden, CO, USA, 2000.

22. Walling, G.A. Co-Firing Switch Grass. In Proceedings of the Advanced Coal Workshop, Provo, UT, USA, 15-16 March 2005.

23. Van Eijk, R.J.; Obernberger, I.; Supancic, K. Options for Increased Utilization of Ash from Biomass Combustion and Co-Firing; KEMA: Arnhem, The Netherlands, 2012.

24. American Coal Ash Association (ACAA). Coal Combustion Products Production \& Use Statistics; ACAA: Farmington Hills, MI, USA, 2009.

25. Patumsawad, S. Co-Firing Biomass with Coal for Power Generation. In Proceedings of the 4th Biomass-Asia Workshop "Biomass: Sources of Renewable Bioenergyand Biomaterial", Shah Alam, Malasia, 20-22 November 2007.

26. Cofiring Biomass - What to Look for if Considering. Available online: http://www.brighthub.com/ engineering/mechanical/articles/107195.aspx\# (accessed on 11 October 2012)

27. Livingston, W.R. Options for High Percentage Biomass Cofiring in New Power Plants. In Proceedings of the IEA Bioenergy Task 32 Workshop, Hamburg, Germany, 30 June 2009.

28. Willeboer, W. Biomass-Coal Cofiring in Present and Future Power Blocks. In Proceedings of the Workshop on Increasing Biomass Cofiring Percentages in Existing Power Plants, Geertruidenberg, The Netherlands, 21 October 2008.

29. Dai, J.J.; Sokhansanj, S.; Grace, J.R.; Bi, X.T.; Lim, C.J.; Melin, S. Overview and some issues related to co-firing biomass and coal. Can. J. Chem. Eng. 2008, 86, 367-386.

30. Hughes, E.E.; Tillman, D.A. Biomass Cofiring: Status and Prospects 1996. In Proceedings of the Engineering-Foundation Conference Biomass Usage for Utility and Industrial Power, Snowbird, UT, USA, April 28-May 02 1996; pp. 127-142. 
31. Mani, S.; Tabil, L.G.; Sokhansanj, S. Grinding performance and physical properties of wheat and barley straws, corn stover and switchgrass. Biomass Bioenergy 2004, 27, 339-352.

32. Spliethoff, H.; Hein, K.R.G. Effect of co-combustion of biomass on emissions in pulverized fuel furnaces. Fuel Process. Technol. 1998, 54, 189-205.

33. Arias, B.; Pevida, C.; Rubiera, F.; Pis, J.J. Effect of biomass blending on coal ignition and burnout during oxy-fuel combustion. Fuel 2008, 87, 2753-2759.

(C) 2013 by the authors; licensee MDPI, Basel, Switzerland. This article is an open access article distributed under the terms and conditions of the Creative Commons Attribution license (http://creativecommons.org/licenses/by/3.0/). 